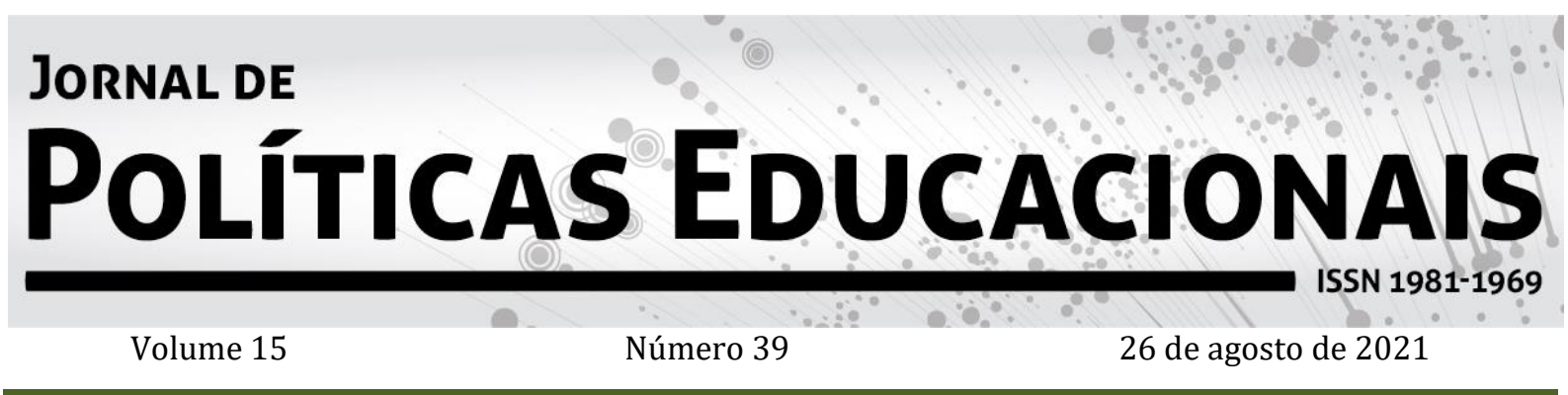

\title{
O Sistema de Ensino Aprende Brasil e o processo de privatização em educação
}

\section{The Aprende Brasil Teaching System and the privatization process in education}

\section{El Sistema de Ensino Aprende Brasil y el proceso de privatización en educación}

\author{
Juliana Selau Lumertr?
}

Citação: LUMERTZ, J. S. O Sistema de Ensino Aprende Brasil e o processo de privatização em educação. Jornal de Políticas Educacionais. V. 15, n. 39. Agosto de 2021.

http://10.5380/ipe.v15i0.80482

Resumo: Este artigo tem como objetivo discutir a entrada do setor privado na educação e como ele redefine o setor público intervindo nas políticas e práticas educacionais. Será apresentada a relação público-privada entre o Sistema de Ensino Aprende Brasil (SEAB) do Grupo Positivo e a Secretaria Municipal de Educação de Gravataí / RS, debatendo os processos de privatização. As políticas sociais são atingidas fortemente pelas políticas neoliberais e os processos de privatização se consolidam. Na educação eles aparecem com diferentes contornos: ora surge como uma parceria entre público e o privado, com a rede de ensino ou diretamente com as escolas, em que a iniciativa privada assume a responsabilidade pela gestão e/ou pelo pedagógico da escola. Ora aparece vendendo serviços educacionais e tecnologias para as escolas públicas, fornecendo proposta de conteúdo e execução para o setor público. A lógica privatista implica retrocesso para a democracia na educação pública e o papel da escola é de fundamental importância na construção de uma sociedade democrática. É o caso do Sistema de Ensino Aprende Brasil do Grupo Positivo no município de Gravataí/RS. O currículo escolar passa a ser definido por meio do sistema apostilado de ensino em que o município o paga para adquirir.

Palavras-chave: Privatização, Neoliberalismo, Educação.

Abstract: This article aims to discuss the entry of the private sector in education and how it redefines the public sector intervening in educational policies and practices. It will be presented the public-private relation between the Aprende Brasil Teaching System (SEAB) of the Positive Group and the Municipal

\footnotetext{
${ }^{1}$ Possui graduação em Pedagogia, Mestrado em Educação, Doutoranda em Educação do Programa de PósGraduação em Educação da Universidade Federal do Rio Grande do Sul (UFRGS), na linha de pesquisa "Políticas e Gestão de Processos Educacionais". Integrante do Grupo de Pesquisa Relações entre o Público e o Privado em Educação (GPRPPE). É professora da educação básica da rede municipal de Porto Alegre. Porto Alegre. Rio Grande do Sul. Brasil. Orcid: https://orcid.org/0000-0002-8204-6234 E-mail: juliana.lumertz@gmail.com
} 


\section{JORNAL DE Políticas EduCACIONAIS \\ ISSN 1981-1969}

Education Department of Gravataí, Rio Grande do Sul State, debating privatization processes. Social policies are strongly affected by neo-liberal policies and then the privatization processes are consolidated. In education they appear with different outlines: as a public-private partnership with the teaching network or directly among schools, in which private iniciative assumes responsibility for the management and/or pedagogical sector of school. They can also sell educational services and technologies for public schools, providing content proposal and implementation for public sector. The privatistic logic implies retrocession for the democracy in the public education. Therefore, the school's role is of fundamental importance to the construction of a democratic society. The Positive Group's Aprende Brasil Teaching System, in Gravataí/RS, is an example of it. The school curriculum is now defined by the handout teaching system in which the municipality pays to acquire it.

Keywords: privatization, neoliberalism, education.

Resumen: Este artículo tiene como objetivo discutir la entrada del sector privado en la educación y cómo este redefine el sector público interviniendo en las políticas y prácticas educativas. Será presentada la relación público-privada entre el Sistema de Ensino Aprende Brasil (SAEB) del Grupo Positivo y la secretaría de educación del municipio brasileño de Gravataí, Rio Grande do Sul, debatiendo los procesos de privatización. Las políticas neoliberales influyen fuertemente en las políticas sociales y los procesos de privatización se consolidan. En la educación dichos procesos aparecen con distintos contornos. Ora surge como una alianza entre público y privado, con la red de enseñanza o directamente con las escuelas, en la que la iniciativa privada asume la responsabilidad por la gestión o por el sector pedagógico de la escuela. Ora aparece vendiendo servicios educativos y tecnologías para las escuelas públicas, proveyendo propuestas de contenido y ejecución para el sector público. La lógica privatista implica retroceso para la democracia en la educación pública y el papel de la escuela es de fundamental importancia en la construcción de una sociedad democrática. Es el caso del Sistema de Ensino Aprende Brasil del Grupo Positivo en el municipio de Gravataí. El currículo escolar pasa a ser definido por medio de un sistema de materiales didácticos que el municipio compra.

Palabras Clave: Privatización, Neoliberalismo, Educación.

\section{Introdução}

Este texto objetiva debater sobre a entrada do setor privado na educação e como ele redefine o setor público e intervém nas políticas e práticas educacionais. Para tal feito apresentamos a relação público-privada entre o Sistema de Ensino Aprende Brasil (SEAB), do Grupo Positivo, e a Secretaria Municipal de Educação de Gravataí/RS, discutindo sobre os processos de privatização.

Conforme Peroni (2018), a relação entre o público e o privado na educação não se limita apenas à propriedade, mas também precisa ser entendida como um projeto societário, estando vinculado ao mercado com um intenso impacto para a construção de uma sociedade democrática.

A construção de uma sociedade mais justa e democrática passa necessariamente pela educação, entendida e garantida constitucionalmente como um direito público de 


\section{JORNAL DE Políticas Educacionals \\ ISSN 1981-1969}

todos e mantida pelo Estado, mas que vem paulatinamente disputando espaço com o setor privado, por meio das reformas neoliberais que permitem o ingresso de instituições privadas e da lógica mercantil no campo educacional.

A influência do setor privado sobre o sistema público, conforme Peroni (2018), está na passagem do público para o terceiro setor ou mesmo para o privado, seja com repasse da propriedade, seja com a permanência da direção da esfera pública, mas assumindo a lógica do mercado. Para entender esse movimento, apresentaremos em três partes, neste artigo, como isso ocorre. A primeira parte visa compreender como a reforma do estado brasileiro cria condições favoráveis para os processos de privatização em educação. A segunda parte do texto busca entender como ocorre a privatização na e da educação (RIKOWSKI, 2017), e na terceira parte apresentaremos a materialização desse processo por meio da parceria público-privada entre o Grupo Positivo e Gravataí, município da região metropolitana de Porto Alegre, no estado do Rio Grande do Sul.

\section{0 público e o privado na educação e a relação com a reforma do Estado}

A relação entre o público e o privado na educação materializa-se num contexto de correlação de forças na sociedade, num momento particular do capitalismo, em que não é o Estado quem determina as relações econômicas, mas é por elas determinado.

Para entender esse momento particular do capitalismo, faz-se necessário retroceder algumas décadas na história, e entender o movimento pós segunda guerra, no qual o controle do trabalho, das tecnologias, dos hábitos de consumos e das configurações de poder político-econômico formularam sua base. 0 crescimento econômico e social, resultante desse movimento, transformou profundamente a sociedade.

Para obter lucros mais seguros, o capital corporativo ajustou sua força de trabalho organizado, assumindo novos papeis e funções relacionadas ao desempenho do mercado e processo produtivo (HARVEY, 1989). 0 fordismo se expande mundialmente e os Estados Unidos conseguem domínios geopolíticos e alianças militares para relações de poder. 


\title{
JORNAL DE Políticas EducacionaIS \\ ISSN 1981-1969
}

As políticas foram direcionadas para outras áreas de investimento e o estado capitalista passou a assumir diferentes obrigações com uma crescente produção em massa de mercadorias. Com a produção em massa, as políticas sociais se redirecionam e garantem, mesmo que relativamente, um pleno emprego aos trabalhadores. Governos complementavam o salário social através da seguridade social, assistência médica, educação, habitação etc. 0 Estado regulava direta ou indiretamente os acordos salariais e os direitos trabalhistas na produção.

Para Harvey (1989) configura-se, nesse contexto, o Estado de Bem-Estar Social, sendo importante salientar que este não ocorreu da mesma forma em todos os países e, conforme Lumertz (2008, p. 21) “[...] mesmo naqueles países onde o capitalismo era mais desenvolvido, ele não conseguia atingir a todos os trabalhadores".

Mas a produtividade e a lucratividade entraram em queda o que ocasionou uma crise fiscal, acelerando a inflação e prejudicando o dólar como moeda-reserva internacional estável. Era o indício de que o poder estadunidense de regulamentação do sistema financeiro internacional estava sendo reduzido.

Conforme Lumertz (2008, p. 22),

\begin{abstract}
A Organização dos Países Exportadores de Petróleo (OPEP) aumenta os preços do petróleo e os árabes embargam as exportações de petróleo para o Ocidente, durante a guerra árabe-israelense em 1973. Buscou-se com isso uma economia de energia através da mudança tecnológica e organizacional, levando ao problema da reciclagem de petrodólares excedentes, desestabilizando os mercados financeiros mundiais.
\end{abstract}

A economia capitalista passa a vivenciar uma crise e passa por um processo de reestruturação do capital que teve como finalidade a recuperação de seu ciclo de produção. As estratégias lançadas pelo capital para se reerguer foram o Neoliberalismo, a Terceira Via, a Globalização e a Reestruturação Produtiva.

Para fins deste artigo focaremos no Neoliberalismo, pois entendemos que ele é parte fundamental para compreendermos a relação entre o público e o privado na educação hoje. 


\section{JORNAL DE Políticas Educacionals

Neoliberalismo, reforma do Estado e educação

Para o Neoliberalismo o Estado passa por uma crise porque ao atender as políticas sociais ocorreu um aumento de gastos públicos ocasionando a crise fiscal. A solução para a crise, portanto, seria a fragilização da democracia por meio da privatização e da desregulamentação, o que provocaria o desmantelamento do Estado, ou seja, o Estado mínimo. Peroni (2006, p. 14) alerta que esse Estado mínimo é proposto somente para as políticas sociais, pois acaba sendo “[...] máximo para o capital, pois, de um lado, ele é chamado a regular as atividades do capital corporativo no interesse da nação [...]" e por outro, é preciso criar um “[...] bom clima de negócios para atrair o capital financeiro transnacional e global e conter (por meios distintos dos controles de câmbio) a fuga de capital para pastagens mais verdes e lucrativas" (PERONI, 2006, p. 14). As políticas sociais passam por um processo de privatização que acabam alterando o papel do Estado para com as políticas sociais, já que racionaliza recursos e esvazia o poder de instituições públicas num projeto claro de sociedade sob a égide capitalista.

A crise de 2008 do neoliberalismo, para Puello-Socarrás (2008), estaria trazendo uma atualização local e global do próprio neoliberalismo e não seu fim. É importante ressaltar que a crise de 2008 deu novas particularidades ao neoliberalismo com as reformas de segunda geração do Consenso de Washington redefinindo o papel do Estado de um Estado mínimo para um Estado essencialmente empresarial e trouxe relações com o neoconservadorismo que acabam por redefinir as fronteiras entre o público e o privado que se materializam em políticas sociais, sobretudo as educacionais para promover,

[...] un dominio que desvincula 'lo público' de 'lo estatal' en una especie de 'espacio público-privado', o como se lo ha denominado un 'espacio público noestatal' que resulta abierta y fundamentalmente mercantil (como el mismo status ontológico del Mercado: un dominio que no es exclusivamente privado sino estrictamente público-privado, es decir, un locus público donde las mercancías tienen la posibilidad de intercambiarse entre ellas para posteriormente privatizarse). (PUELLO-SOCARRÁS, 2008, p. 108) 


\section{JORNAL DE Políticas EducacionaIS ISSN 1981-1969 \\ O Estado repassa ao setor privado a execução de políticas sociais com} características gerenciais, que é o caso do Sistema de Ensino Aprende Brasil, do Grupo Positivo, que é adquirido pelo governo municipal por meio da compra de um Sistema Educacional. Para o autor trata-se de um governo empresarial, no qual presta serviços sociais por intermédio do mercado.

O neoliberalismo avançou mundialmente defendendo a privatização de direitos sociais e limitando a intervenção do Estado na economia assentindo por vezes um avanço local, mas com retrocessos internacionais. Nesse sentido, com o crescimento do debate em torno dos direitos houve também o debate acerca da necessidade de uma reforma do Estado que revisse a atuação do governo na política social e em questões importantes que acabam se opondo ao movimento pela redemocratização da sociedade (PIRES, 2018).

Durante a década de 1990 as políticas neoliberais no Brasil tiveram forte influência nas políticas sociais iniciadas no governo Fernando Collor de Mello e seguidas por Fernando Henrique Cardoso. A saída para a crise fiscal estaria em reformar o Estado por meio do Plano de Reforma do Aparelho do Estado, de 1995. A proposta foi aderir a uma administração gerencial, incluindo, nesse âmbito, a educação.

Na década de 2000, até o ano de 2016, com governos brasileiros mais alinhados aos campos progressistas e com o golpe parlamentar da Presidenta Dilma Roussef as políticas de austeridade fiscal neoliberais intensificaram-se e estão em seu auge no governo de Jair Messias Bolsonaro representando um campo político da nova direita econômica.

\section{Processos de privatização em educação}

Este item propõe-se a compreender o impacto do mercado na educação pública, influenciado pela nova direita no setor educacional, buscando entender as formas de privatização que inserem a lógica mercantil na educação e sua relação entre o público e o privado. As políticas de austeridade e a severa recessão econômica acabaram reduzindo o investimento em políticas sociais e concentraram a riqueza nas mãos da elite, 


\section{JORNAL DE PolítICAS EduCACIONAIS \\ ISSN 1981-1969}

exacerbando a desigualdade social. Uma nova direita brasileira surge em meio a tal recessão regulada por “[...] propostas de políticas públicas pautadas em reformas e privatizações da estrutura estatal, até privatização das próprias formas de gestão do Estado e suas funções sociais" (CASIMIRO, 2018, p. 465).

A nova direita, segundo Casimiro (2018), opera de forma articulada e institucionalizada, conduzindo à doutrina e ao domínio da burguesia hegemônica, sendo um agravante para a construção democrática, principalmente na educação, porque vai impregnando-a com a lógica empresarial, reduzindo cada vez mais os direitos sociais dando poder a uma classe que quer transformar o dinheiro público em lucro. Nesse sentido, as políticas sociais públicas são mercantilizadas no sentido de atender aos anseios dessa nova direita, investindo contra a democratização da sociedade.

No Brasil, o processo de redemocratização da sociedade vivido pós ditadura militar, na década de 1980, coincidiu com o auge do neoliberalismo. Com a reforma estatal da década de 1990, já citada no item anterior, os processos de democratização eram vistos como um empecilho ao livre andamento do mercado, tendo como solução o repasse, para a iniciativa privada, do controle de políticas públicas e sociais. Os recursos utilizados, portanto, foram os processos de privatização dos serviços públicos, redefinindo o papel do Estado na garantia do direito à educação. Os processos de privatização atuam tanto na direção quanto na execução de políticas sociais (PERONI, 2018), tendo como lógica o Estado empresarial, como já citamos anteriormente.

A privatização pode ocorrer na e $d a$ educação, é parte do próprio desenvolvimento capitalista e transforma a receita do Estado em lucro privado, ou seja, a educação é um investimento em capital por meio da privatização. A privatização ocorre de duas maneiras básicas: a primeira delas é a privatização clássica, ou seja, transferência da propriedade dos ativos públicos para o setor privado, e a segunda como tomada de controle sobre a educação por parte das empresas (RIKOWSKI, 2017).

As empresas que controlam a educação o fazem por meio do contrato, no qual o gestor privado se beneficia da diferença entre os pagamentos feitos pelos governos e o que realmente custa para administrar. Trata-se da conversão da receita do Estado em 


\section{JORNAL DE Políticas EducacionaIS \\ ISSN 1981-1969}

lucro privado por meio da administração ou compra de instituições e serviços educacionais (RIKOWSKI, 2017). Para o autor é a capitalização da educação gerando mercadoria e mercantilização, estabelecendo o mercado educacional que é crucial para esse processo.

A mercantilização está atrelada à mercadificação, onde tudo vira mercadoria, por exemplo, uma política de publicidade e persuasão por meio de grandes grupos, como lobistas, meios de comunicação e think tanks; a comercialização na educação (propaganda em livros didáticos, produtos de tecnologias da informação e até mesmo anúncios filantrópicos dentro das escolas ou na televisão); produção de produtos (mercadorias) como videoaulas, softwares e produtos para gerentes educacionais; por último, o mercado de tecnologia da informação: avaliação, monitoramento e vigilância - circuito de TV (RIKOWSKI, 2017).

Faz parte da capitalização, a monetização de atividade, produtos, processos e procedimentos que recebem preços ligados “[...] à medição de serviços educacionais, que por sua vez podem ser divididos em padronização, garantia e controle de qualidade, relação custo-benefício e muitos outros conceitos subsidiários" (RIKOWSKI, 2017, p. 406).

Para Peroni (2018), o processo de privatização educacional ocorre de diferentes formas. Ele pode se dar por meio da alteração da propriedade, em que o público é repassado ao terceiro setor ou para o setor privado; pode ser por meio das parcerias público-privadas com ou sem fins lucrativos; ou ainda pode ocorrer da forma em que a propriedade estatal passa a ter a lógica de mercado, reorganizando principalmente os processos de gestão e redefinindo o conteúdo da política educacional. Portanto, o conteúdo da educação passa a ser definido pelo setor privado, que adere à lógica mercantil na administração pública por meio da gestão gerencial.

A oferta da educação permanece pública e a privatização ocorre no "[...] conteúdo da proposta [...]", com a lógica mercantil no pedagógico e na organização da escola pública (PERONI, 2015, p. 27). Esses processos de privatização em educação redimensionam a escala de democratização da educação pública e reorganiza a educação enquanto bem 


\section{JORNAL DE Políticas Educacionals \\ ISSN 1981-1969}

público guiado pela lógica de mercado. Para melhor compreensão desses processos de privatização em educação, apresentaremos o Grupo Positivo, que tem parceria com o município de Gravataí/RS.

\section{O Grupo Positivo e o Sistema de Ensino Aprende Brasil ${ }^{2}$}

O Grupo Positivo (GP) é uma holding 3 brasileira que fica situada em Curitiba/PR, atua em todo o Brasil e em mais de 40 países. Foi fundada em 1972 e seus primeiros empreendimentos foram uma gráfica e um cursinho pré-vestibular. Atualmente opera no ensino privado, vende soluções educacionais para a rede pública e atua na área de tecnologia e gráfico-editorial. Além da empresa, foi fundado em 2012, o Instituto Positivo, que atua como gestor do investimento social privado do GP direcionando seus projetos para área da educação e desde 2015 atuando fortemente nos Arranjos de Desenvolvimento da Educação (ADEs).

Neste artigo apresentaremos o Sistema de Ensino Aprende Brasil (SEAB), fruto da parceria entre o município de Gravataí e o Grupo Positivo, que consiste na venda de um “[...] conjunto de soluções específicas [...]” (SISTEMA..., [201-], documento eletrônico) para a rede de ensino, contendo livros didáticos, assessoria pedagógica, sistema de avaliação e gestão online, visando atender alunos do primeiro ao quinto ano do ensino fundamental.

A cidade de Gravataí está localizada na região metropolitana de Porto Alegre, à 22 quilômetros da capital do Rio Grande do Sul. Sua população é de 273.742 habitantes (IBGE, 2016), é o quinto maior PIB do estado. A economia gira em torno do polo industrial, com destaque para a fábrica automotiva da General Motors (GM).

\footnotetext{
${ }^{2}$ Sobre trabalhos acadêmicos do Grupo Positivo, ver Carvalho (2018; 2019) e Domingues (2017).

3 Uma holding é uma empresa que atua como controladora de outras companhias, detendo participação majoritária nas ações de suas subsidiárias. Holding não é um tipo societário, mas uma forma de administração de grupos empresariais que visa a redução da carga tributária, retorno de capital sob a forma de lucro isento e planejamento da sucessão. Formalizada juridicamente no Brasil com a lei número 6.404/76, conhecida como Lei das Sociedades Anônimas, as holdings podem ser de dois tipos: puras, que têm em seu objeto social apenas o controle das ações de outras companhias, ou mistas, que também produzem bens ou serviços.". Disponível em: https://www.dicionariofinanceiro.com/. Acesso em: 23 jun. 2020.
} 


\section{JORNAL DE Políticas Educacionals

A rede municipal de ensino de Gravataí é uma das maiores redes do estado, possuindo 02 escolas especiais, 11 escolas de educação infantil, 60 escolas de ensino fundamental e 01 escola de ensino médio.

No ano de 2014 o município passou a adquirir o Sistema de Ensino Aprende Brasil (SEAB), da Editora Positivo, que consiste em um sistema privado de ensino que tem por objetivo elevar a qualidade do ensino público potencializando as aprendizagens dos anos iniciais do ensino fundamental.

O SEAB é um "[...] um sistema de ensino completo, que oferece um conjunto específico de soluções para a rede de ensino pública [...]", que vai desde o "[...] Livro Didático Integrado, Assessoria Pedagógica, Aprende Brasil On e os Sistemas hábile e simeB" (SISTEMA..., [201-], documento eletrônico).

O livro didático integrado e o livro digital são compostos por 4 volumes anuais. 0 município também recebe os livros do Programa Nacional do Livro Didático (PNLD). Os materiais didáticos são distribuídos aos professores e alunos. 0 sistema apostilado acaba definindo o conteúdo da educação pública no município.

Conforme dados do GP, a assessoria pedagógica à capacitação dos docentes e também da equipe técnica da rede de ensino é uma complementação feita de forma presencial e à distância. Essa assessoria pedagógica conta com uma equipe de apoio disponível aos municípios para auxiliar no trabalho tanto dos professores, quanto dos gestores.

Faz parte também o Aprende Brasil On que é uma plataforma digital de aprendizagem com diferentes recursos que fazem o gerenciamento da aprendizagem. A plataforma virtual de aprendizagem conta com materiais para alunos, professores, gestores e famílias.

Disponibilizam também "[...] duas ferramentas para a gestão e mensuração do avanço da educação de sua rede de escolas: o simeB e o hábile" (SISTEMA..., [201-], documento eletrônico). Esses sistemas de gestão e de avaliação disponibilizam diagnósticos sobre o desempenho da rede, bem como das escolas e dos alunos. 


\section{JORNAL DE Políticas Educacionals

O hábile é um sistema de avaliação educacional externo de aprendizagem em larga escala nas áreas de Língua Portuguesa, Matemática e Ciências. Já o Sistema de Monitoramento Educacional do Brasil (simeB) é uma ferramenta de gestão educacional no qual são feitos diagnósticos, planejamentos e monitoramentos de metas que foram estabelecidas pela rede de ensino.

A parceria existe desde 2014 e o financiamento municipal foi utilizado para a aquisição do Sistema de Ensino Aprende Brasil. A seguir mostraremos todo o investimento público feito até o ano de 2021.

Tabela 1 - Valores dos contratos ente o Município de Gravataí e a Editora Positivo

\begin{tabular}{ll}
\hline ANO & VALOR (R\$) \\
\hline 2014 & $3.872 .887,20$ \\
2015 & $4.263 .950,00$ \\
2016 & $4.492 .638,00$ \\
2017 & $4.629 .996,00$ \\
2018 & $4.901 .376,00$ \\
2019 & $5.877 .300,00$ \\
2020 & $6.246 .300,00$ \\
2021 & $5.900 .294,40$ \\
TOTAL & $40.184 .741,60$
\end{tabular}

Fonte: elaborada pela autora a partir dos Contratos de Compra e Venda (GRAVATAÍ, 2013; 2015; 2016; 2017 ; 2018; 2019; 2020; 2021).

Para a compra do sistema de ensino foram gastos $\mathrm{R} \$ 40.184 .741,60$ (quarenta milhões, cento e oitenta e quatro mil, setecentos e quarenta e um reais e sessenta centavos). Os recursos usados para adquirir os produtos são destinados ao setor privado, gerando lucro para eles via receita pública. Quando esse recurso é enviando para a iniciativa privada, que presta serviços educacionais com regras definidas, entendemos que a lógica do mercado está sendo introduzida no setor público, reorganizado o processo de gestão e redefinindo a execução, a direção e o conteúdo da política educacional (ROSSI; LUMERTZ; PIRES, 2018). 


\section{JORNAL DE Políticas Educacionals \\ ISSN 1981-1969}

Importante ressaltar que a propriedade permanece pública. A escola continua sendo pública, mas o gestor define a compra de pacotes educacionais, num processo de privatização com apoio do poder público. É o que Peroni (2018) aponta como privatização como política pública.

\section{Considerações finais}

0 auge do neoliberalismo e a reforma estatal feita do Estado brasileiro aguçaram a austeridade fiscal. A crise de 2008 trouxe novos contornos aos estados trabalhando na lógica de um novo neoliberalismo que se alimenta de crises para sua sobrevivência (LAVAL; DARDOT, 2017).

As políticas sociais são atingidas fortemente e os processos de privatização se consolidam. Na educação eles aparecem com diferentes contornos: ora surge como uma parceria entre público e o privado, com a rede de ensino ou diretamente com as escolas, em que a iniciativa privada assume a responsabilidade pela gestão e/ou pelo pedagógico da escola. Ora aparece vendendo serviços educacionais e tecnologias para as escolas públicas, fornecendo proposta de conteúdo e execução para o setor público. Em ambos os casos o processo de democratização da educação pública é deixado de lado, já que o setor privado acaba definindo regras, geralmente vinculadas ao mercado.

Com o argumento de melhorar os índices e a qualidade da educação pública, gestores acabam escolhendo um projeto de educação privatizada. Essa privatização pode ocorrer via direção ou via execução e o conteúdo da educação passa a ser ditado pelo mercado, num projeto claro de sociedade num contexto de luta de classes.

A lógica privatista implica retrocesso para a democracia na educação pública e o papel da escola é de fundamental importância na construção de uma sociedade democrática. É o caso do Sistema de Ensino Aprende Brasil do Grupo Positivo no município de Gravataí/RS. O currículo escolar passa a ser definido por meio do sistema apostilado de ensino em que o município o paga para adquirir. 


\section{JORNAL DE Políticas EducacionaIS \\ ISSN 1981-1969}

O mercado educacional é introduzido na rede municipal de Gravataí não só privatizando-a como também transformando-a em mercadoria e distanciando-se cada vez mais de um direito público essencial do cidadão com base democrática, crítica e coletiva. A educação da rede municipal de Gravataí, que já tinha um histórico de construção democrática, é ressignificada como bem público, retrocedendo os pequenos passos avançados rumo à democratização da educação. A receita pública municipal também é transformada em lucro para o GP, uma vez que o município destina verbas para a aquisição do Sistema de Ensino Aprende Brasil.

A iniciativa privada define a formação de professores e de gestores escolares, ignorando o processo participativo, criativo e democrático da educação. Nesse caso, não ocorre mudança de propriedade em si, mas pressupõe-se que há um projeto societário de desdemocratização, corrompendo a escola pública impondo a lógica de marcado baseada no individualismo e na competitividade.

\section{Referências}

BRASIL. Ministério da Educação. Plano Diretor de Reforma do Aparelho do Estado. Brasília, 1995. Disponível em: <http://www.planalto.gov.br/publi_04/ COLECAO/PLANDI.HTM>. Acesso em: 10 fev. 2021.

CASIMIRO, Flávio Henrique Calheiros. A nova direita: aparelhos de ação política e ideológica no Brasil contemporâneo. São Paulo: Expressão Popular, 2018.

FREITAS, Luiz Carlos de. A reforma empresarial da educação: nova direita, velhas ideias. São Paulo: Expressão Popular, 2018.

GRAVATAÍ. Portal do Cidadão. Gravataí, [201-]. Disponível em: https://gravatai.atende.net. Acesso em: 19 maio 2019.

GRAVATAÍ. Secretaria Municipal de Planejamento e Programação Orçamentaria.

Contrato de compra e venda N. 014/2013. Gravataí, 2013.

GRAVATAÍ. Secretaria Municipal de Planejamento e Programação Orçamentaria. Contrato de compra e venda N. 001/2015. Gravataí, 2015. 


\section{JORNAL DE Políticas Educacionais \\ ISSN 1981-1969}

GRAVATAÍ. Secretaria Municipal de Administração. Contrato de compra e venda N. 001/2016/ Inexigibilidade N. 019/2016. Gravataí, 2016.

GRAVATAÍ. Secretaria Municipal de Administração. Contrato de compra e venda N. 001/2017 / Inexigibilidade N. 020/2016. Gravataí, 2017.

GRAVATAÍ. Departamento de Administração Financeira. Contrato de compra e venda N. 001/2018 / Inexigibilidade N. 002/2018. Gravataí, 2018.

GRAVATAÍ. Departamento de Administração Financeira. Contrato de compra e venda N. 001/2019 / Inexigibilidade N. 009/2019. Gravataí, 2019.

GRAVATAÍ. Departamento de Administração Financeira. Contrato de compra e venda N. 002/2020 / Inexigibilidade N. 008/2020. Gravataí, 2020.

HARVEY, David. Condição pós-moderna. 4. ed. São Paulo: Loyola, 1989. LAVAL, Christian; DARDOT, Pierre. La pesadilla que no acaba nunca. Barcelona: Gedisa, 2017.

LUMERTZ, Juliana Selau. A parceria público-privada na educação: implicações para a gestão da escola. 2008. Dissertação (Mestrado em Educação) - Programa de PósGraduação em Educação, Faculdade de Educação, Universidade Federal do Rio Grande do Sul, Porto Alegre, 2008.

PERONI, Vera Maria Vidal. Perspectivas da gestão democrática da educação: avaliação institucional. In: LUCE, Maria Beatriz; MEDEIROS, Isabel Letícia Pedroso de (org.).

Gestão Escolar Democrática: concepções e vivências. Porto Alegre: Ed. da UFRGS, 2006. p. 149-156.

PERONI, Vera Maria Vidal. Diálogos sobre as redefinições do papel do Estado e nas fronteiras em o público e o privado na educação. São Leopoldo: Oikos, 2015.

PERONI, Vera Maria Vidal. Múltiplas formas de materialização do privado na educação básica púbica no Brasil: sujeitos e conteúdo da proposta. Currículo Sem Fronteiras, Porto Alegre, v. 18, n. 1, p. 212-238, jan. 2018.

PIRES, Daniela de Oliveira. Os desafios para a consolidação do estado social e de direito brasileiro e as consequências para a gestão democrática da educação. In: PERONI, Vera Maria Vidal; LIMA, Paula Valim; KADER, Carolina Rosa. Redefinições das fronteiras entre o público e o privado: implicações para a democratização da educação. São Leopoldo: Oikos, 2018. p. 105-114. 


\section{JORNAL DE Políticas EducacionaIS \\ ISSN 1981-1969}

PUELLO-SOCARRÁS, José Francisco. Nueva gramática del Nel-liberalismo: Itinerarios teoricos, trayectorias intelectuales, claves ideologicas. Bogotá: Universidad Nacional de Colombia, Facultad de Derecho, Ciencias Políticas y Sociales, 2008.

RIKOWSKI, Glenn. Privatização em Educação e formas de mercadoria. Retratos da escola, Brasília, v. 11, n. 1, jul. 2017.

ROSSI, Alexandre José; LUMERTZ, Juliana Selau; PIRES, Daniela de Oliveira. As implicações da parceria público-privada para a gestão democrática da escola pública. In: BAIRROS, Mariângela; MARCHAND, Patrícia Souza. Coordenação Pedagógica concepções e práticas. Porto Alegre: Tomo Editorial, 2018. p. 387-399.

SISTEMA DE ENSINO APRENDE BRASIL. Conheça. Curitiba, [201-]. Disponível em: http://sistemaaprendebrasil.com.br/conheca/. Acesso em: 19 maio 2019. 


\title{
JORNAL DE Políticas Educacionals Volume 15 Número 39

(c)

SORERIGHISRESERVED O Copyright é retido pelo/a autor/a (ou primeiro co-autor) que outorga o direito da primeira publicação ao Jornal de Políticas Educacionais. Mais informação da licença de Creative Commons encontram-se em https://creativecommons.org/licenses/by-nc-nd/4.0. Qualquer outro uso deve ser aprovado em conjunto pelo/s autor/es e pelo periódico.

JoRnAl DE PolíticAS EdUCACIONAIS é uma publicação do Núcleo de Políticas Educacionais do Setor de Educação da Universidade Federal do Paraná - NuPE/UFPR, em consórcio com a Linha de Pesquisa em Políticas Educacionais do Programa de Pós-Graduação em Educação - PPGE/UFPR, que aceita colaboração, reservando-se o direito de publicar ou não o material espontaneamente enviado à redação. As colaborações devem ser enviadas ao NuPE/UFPR, conforme orientações contidas nas páginas do periódico na internet: http://revistas.ufpr.br/jpe.

\section{INDEXACÃO:}

\author{
BASE DE DADOS \\ Sumário.Org \\ Google Scholar \\ $B A S E$ \\ Dimensions \\ Miar \\ DIRETÓRIOS \\ ScieloEduc@ \\ Diadorim \\ DOAJ \\ Erih Plus \\ Latindex \\ EZB \\ $R O A D$ \\ Journal 4-free
}

\author{
ÍNDICES \\ Index Copernicus \\ Cite Factor \\ PORTAIS \\ LiVre \\ Capes \\ Science Open \\ World Wide Science
}

(Periódico integralmente disponível apenas em via eletrônica)

Jornal de Políticas Educacionais / Núcleo de Políticas Educacionais da Universidade Federal do Paraná NuPE/UFPR - v.1, n. 1 (1ํo semestre de 2007) - Curitiba: NuPE/UFPR.

Volume 15, número 39 - Agosto de 2021

ISSN 1981-1969

1. Educação - Periódicos. 2. Política Educacional - Periódicos. I. NuPE/UFPR 


\section{JORNAL DE Políticas Educacionals

Comitê Editorial:

Elisângela Scaff (UFPR)

Daniela de Oliveira Pires (UFPR)

Conselho Editorial:

Adriana Aparecida Dragone Silveira (UFPR-Brasil), Ana Lorena de Oliveira Bruel (UFPR-Brasil), Andréa Barbosa Gouveia (UFPR - Brasil), Angela Maria Martins (FCC, Brasil), Angelo Ricardo de Souza (UFPRBrasil), Antonia Almeida Silva (UEFS, Brasil), Cassia Alessandra Domiciano (UFPR-Brasil), Cesar Tello (Universidad Nacional Tres Febrero, Argentina), Claudia Regina Baukat Silveira Moreira (UFPR-Brasil), Cristiane Machado (Unicamp- Brasil), Elton Luiz Nardi (UNOESC, Brasil), Fernanda Saforcada (Universidad de Buenos Aires - UBA - Argentina), Isaac Paxe (Instituto Superior de Ciências da Educação (ISCED- Luanda, Angola), Gabriela Schneider (UFPR-Brasil), Gladys Beatriz Barreyro (USP - Brasil), Gilda Cardoso Araújo (UFES - Brasil), Gustavo Enrique Fischman (Arizona State University - USA), Janete Maria Lins de Azevedo (UFPE, Brasil), Jefferson Mainardes (UEPG - Brasil), João Ferreira de Oliveira (UFG - Brasil), Jorge Alarcon Leiva (Universidad de Talca - Chile), Jorge Manuel Gorostiaga (UNSAM - Argentina), Juca Gil (UFRGS Brasil), Luciana Rosa Marques (UFPE, Brasil), Marcos Alexandre dos Santos Ferraz (UFPR-Brasil) Marcia Aparecida Jacomini (Unifesp-Brasil), Maria Dilnéia Espíndola Fernandes (UFMS, Brasil), Natalia Oliveira Woolley (UCLA, USA), Ney Cristina Monteiro de Oliveira (UFPA - Brasil), Nicolás Bentancur, (Universidad de la República de Uruguay), Nora Krawczyk (Unicamp- Brasil), Pedro Flores-Crespo (UAQ, México) Rodrigo da Silva Pereira (UFBA, Brasil), Robert Verhine (UFBA - Brasil), Rosana Cruz (UFPI - Brasil), Rubens Barbosa Camargo (USP - Brasil), Sebastián Donoso Díaz (Universidad de Talca - Chile), Theresa Adrião (UNICAMP Brasil), Vera Maria Vidal Peroni (UFRGS - Brasil).

Créditos e Agradecimentos:

Revisão de Língua Portuguesa, Abstract e Resumen: Programa de apoio às publicações científicas periódicas da UFPR

Arte e diagramação: Tiago Tavares (tiagotav@gmail.com)

Jornal de Políticas Educacionais

Universidade Federal do Paraná

Setor de Educação

Núcleo de Políticas Educacionais - NuPE/UFPR

Avenida Sete de Setembro, 2645

2 o andar, Sala 213

80.230-010 - Curitiba - PR - Brasil

Tel.: 41-3535-6264

jpe@ufpr.br

http://revistas.ufpr.br/jpe 